\title{
OZONE LEVELS IN THE RIJEKA BAY AREA, NORTHERN ADRIATIC, CROATIA, 1999-2007
}

\author{
Ana Alebić-Juretić \\ Teaching Institute of Public Health, Rijeka, Croatia
}

\begin{abstract}
The continous ozone monitoring in the Rijeka bay started only in 1999 in the city center (Institute buiding) and was extended to five more sampling sites in 2003. The first evaluation of ozone at four selected sampling sites is given: urban Site 1, resort Site 2, industrial (,fence line“) Site 3 and suburban Site 4 (above the eastern industrial zone). The lowest ozone level was found at Site 1, while the highest was obtained at the suburban Site 4, as expected. All sites exhibit decline in ozone concentrations, the most pronaunced at suburban Site 4, while almost constant at resort site 2. The concentration roses for Site 3 and 4 agree with the prevailing wind directions, pointing to the coastal line, where the major pollution sources are located. In spite of dominant wind ditection from N-NW sector, the dominant sector in concentration rose is SW at Site 1, while there is no distinct direction in the concentration rose at resort Site 2. Due to different meteorological conditions, the $\mathrm{AOT}_{40}$ values differ considerably, e.g. several thousands in 2007 or up to $45.000 \mu \mathrm{ghm}^{-3}$ in 2005 .
\end{abstract}

Key words: air pollution, ozone, trends, concentration roses, $A O T_{40}$

\section{INTRODUCTION}

Ground level ozone is an irritant that affect human respiratory system. Exposure to elevated concentrations of ozone may cause increased hospital admission due to pneumonia, chronic obstructive pulmonary disease, asthma, allergic rhinitis and other respiratory diseases. Ground level ozone is the result of two processes: natural and anthropogenic, as a secondary pollutant formed through photochemical reactions of nitrogen oxides and $\left(\mathrm{NO}_{\mathrm{X}}\right)$ and volatile organic compounds (VOC) at high solar irradiation and temperature (Ebi and McGregor, 2008). Because of two latter conditions, higher concentrations of ozone are found in summer.

Rijeka is an industrialized town in the Northern Adriatic Area, with three big air pollution point sources: old refinery facilities in the wider city center, and new petroleum refinery and power plant in the eastern industrial zone. Though continous air pollution monitoring dates back to mid seventies, the continous ozone monitoring started in the city of Rijeka only in 1999. In 2003 the ozone monitoring was extended to 5 more sampling sites, in the vicinity of the both petroleum refinery facilities, and by 2007 two more monitoring stations were added to the existing local network. This is the first evaluation of ozone level in the Rijeka Bay area.

\section{EXPERIMENTAI}

Location of sampling sites is given on Figure 1:

Site 1 (Rijeka): Institute building in the city centre, $45^{\circ} 19^{\prime} 54^{\prime \prime} \mathrm{N}, 14^{\circ} 25^{\prime} 20^{\prime \prime} \mathrm{E}, 20 \mathrm{~m}$ a.s.l.

Site 2 (Opatija): resort area, 15 km westwards from Rijeka, $45^{\circ} 20^{\prime} 12^{\prime \prime} \mathrm{N}, 14^{\circ} 18^{\prime} 24^{\prime \prime} \mathrm{E}, 40 \mathrm{~m}$ a.s.1.

Site 3 (Urinj): industrial, $12 \mathrm{~km}$ eastwards from Rijeka, $45^{\circ} 12^{\prime} 19^{\prime \prime} \mathrm{N}, 14^{\circ} 31^{\prime} 42^{\prime \prime} \mathrm{E}, 88 \mathrm{~m}$ a.s.l.

Site 4 (Krasica): suburban, 15 km eastwards from Rijeka, above industrial zone, $45^{\circ} 18^{\prime} 30^{\prime \prime} \mathrm{N}, 14^{\circ} 33^{\prime} 06^{\prime \prime} \mathrm{E}, 186$ m a.s.l.

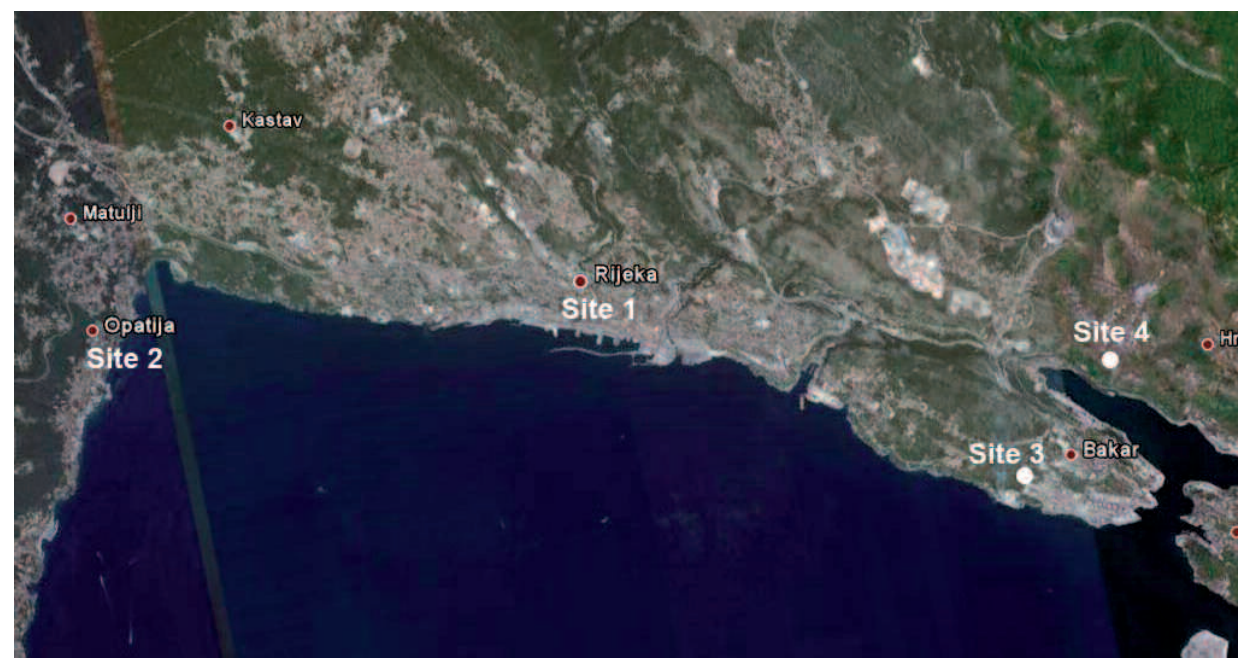

Figure 1. Location of sampling sites: Site 1-urban, Site 2-resort area, Site 3-industrial, Site 4- suburban. 
Ozone analyzers API 200 (San Diego, USA) were used for ozone determination at Sites 1 and 2 Open path DOAS systems (AR 500, Opsis, Sweden) were used for ozone monitoring at Sites 3 and 4 EnviMan modular software package (Opsis, Sweden) was used for data acquisition, elaboration and analyses.

\section{RESULTS AND DISCUSSION}

The lowest ozone levels are found at urban Site 1, at lowest height above sea level and affected by both, industrial and traffic emission of pollutants being sinks of ozone. The highest ozone level was found at Site 4, situated at highest altitude, above night-time mixing height, thus forming reservoir of ozone. Diurnal concentrations of ozone at Sites 1 and 2 are typical for urban areas showing morning and evening minima due to higher $\mathrm{NO}_{\mathrm{X}}$ emission from traffic. Such minima are less visible in suburban sites: Sites 3 and 4.

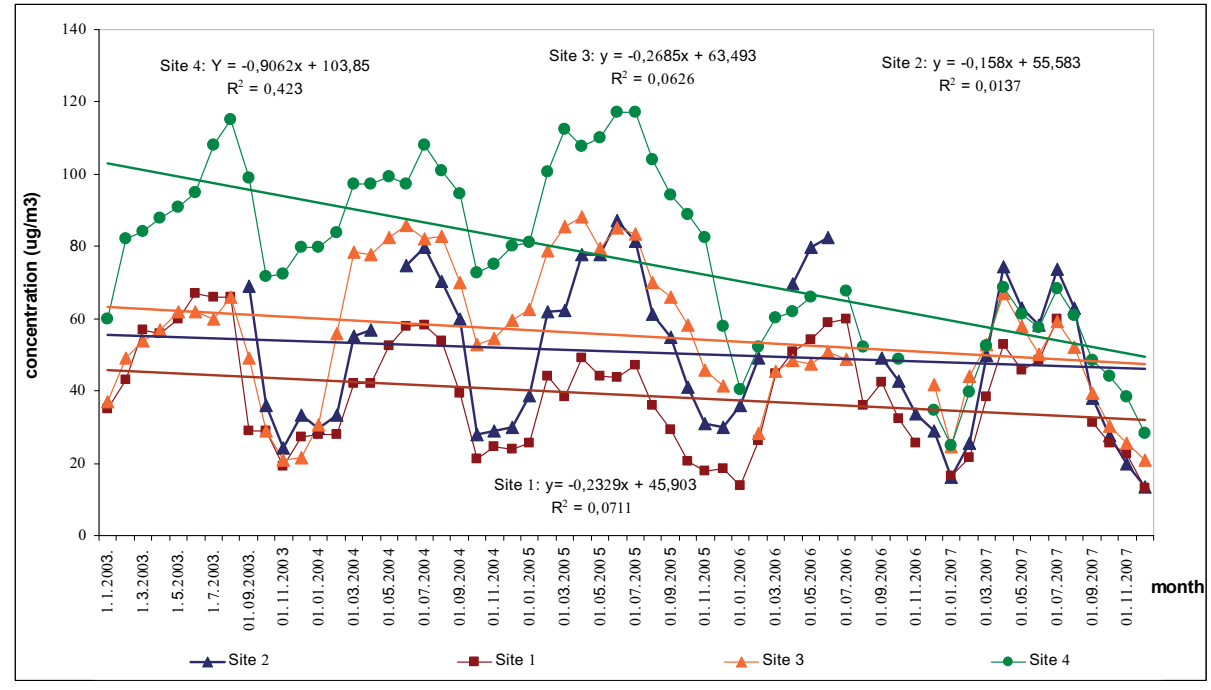

Figure 2. Temporal trend of ozone in the period 2003-2007.

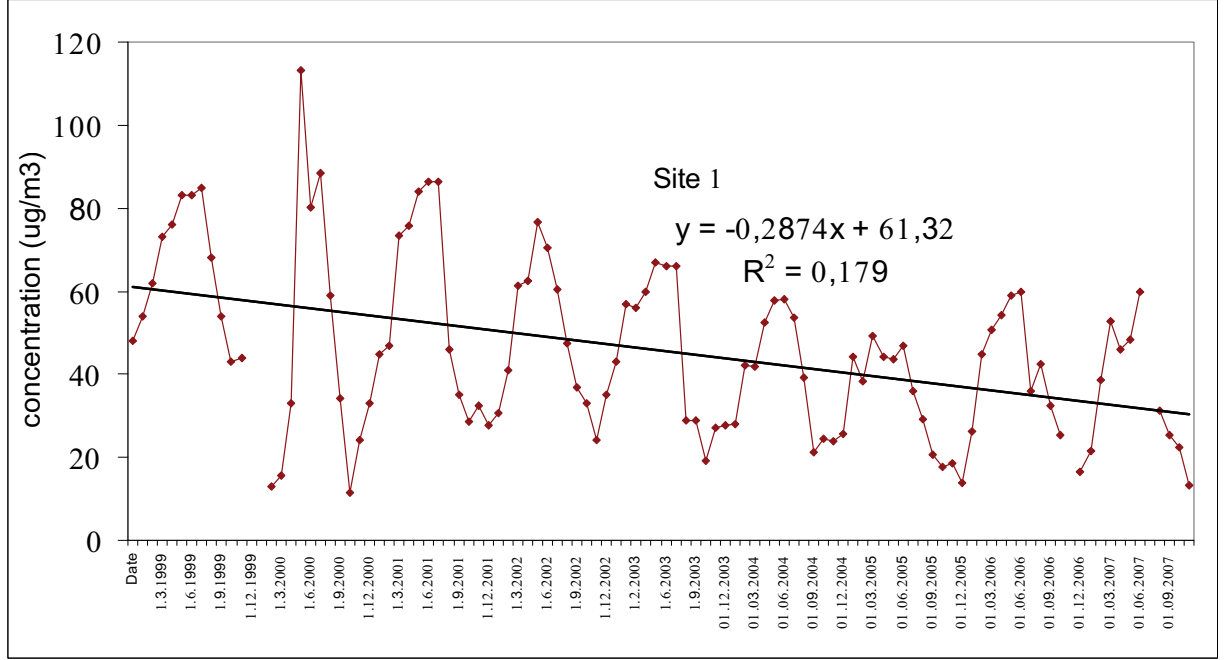

Figure 3. Trend in ozone level at urban Site 1 (Rijeka).

Ozone monthly averages show a decline trend at all sites during the five-years period 2003-2007 (Fig. 2). The same is valid for the extended period 1999-2007 at Site 1 (Fig. 3). This is contrary to the results of some European studies indicating no trend for rural sites and some increase in ozone for urban and traffic sites for the last decade (ETC/ACC, 2007) due to reduced $\mathrm{NO}_{\mathrm{X}}$ emission. In spite of constant total $\mathrm{NO}_{\mathrm{X}}$ emission since 2001, the increase in $\mathrm{NO}_{\mathrm{X}}$ emission from traffic might be the cause of such a downward trend. The declining trend in ozone levels were found in the preceding period 1990-1999 at the Puntijarka (close to Zagreb), approx $150 \mathrm{~km}$ NE from Rijeka, having the longest time series for ozone in Croatia (Butkovic et al, 2002). The long term trend of ozone must be a 
phenomena locally specified, since no temporal ozone trend has been observed in Rome in the period 1991-2000 (Avino and Manigrasso, 2008).

The concentration roses for Site 3 and 4 agree with the prevailing wind directions, pointing to the coastal line, where the major pollution sources are located. In spite of dominant wind ditection from N-NW sector at Site 1, the dominant sector in ozone concentration rose is SW, while at remote Site 2 , there is no distinct direction in the concentration rose, except absence of NE fluxes due to specific orography, schielded from NE winds. Concentration roses indicate prevailing south sectors carrying higher concentrations of ozone at all Sites except Site 2, indicating possible ozone precursor sources at the coastal line (Fig. 4)

Site 1

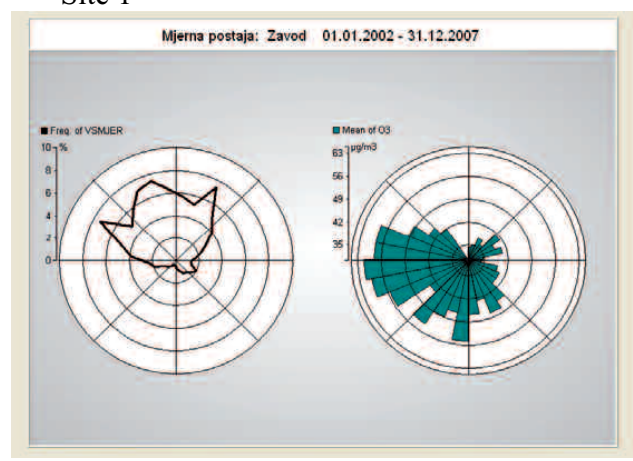

Site 3

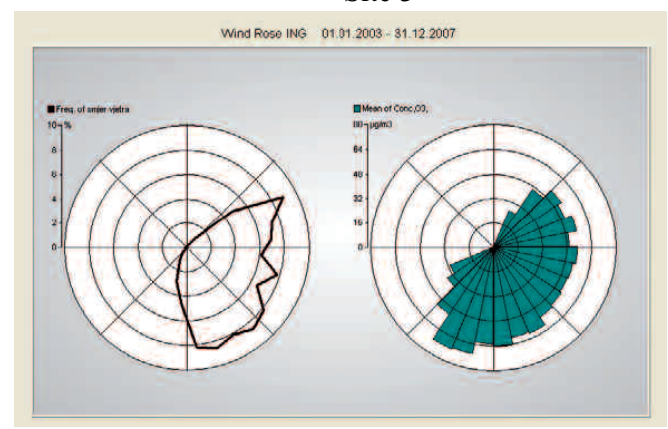

Site 2

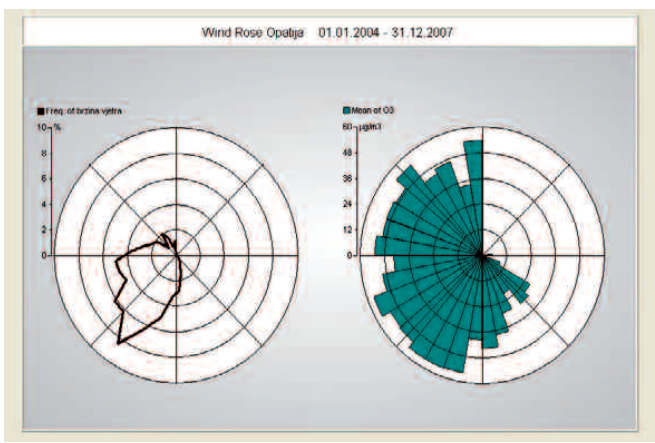

Site 4

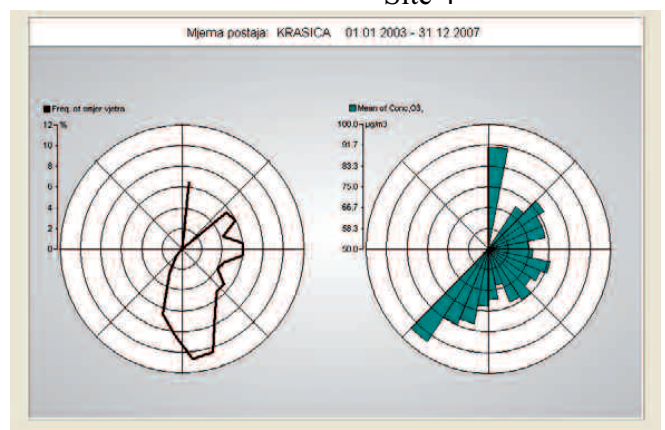

Figure 4. Wind and ozone concentration roses for all selected sites.

Five years average $\mathrm{AOT}_{40}$ values exceed the target value of $18000 \mu \mathrm{ghm}^{-3}$ at Site 4 and Site 2 . The Site 2 is a well known coastal resort with rich Mediterranean vegetation.

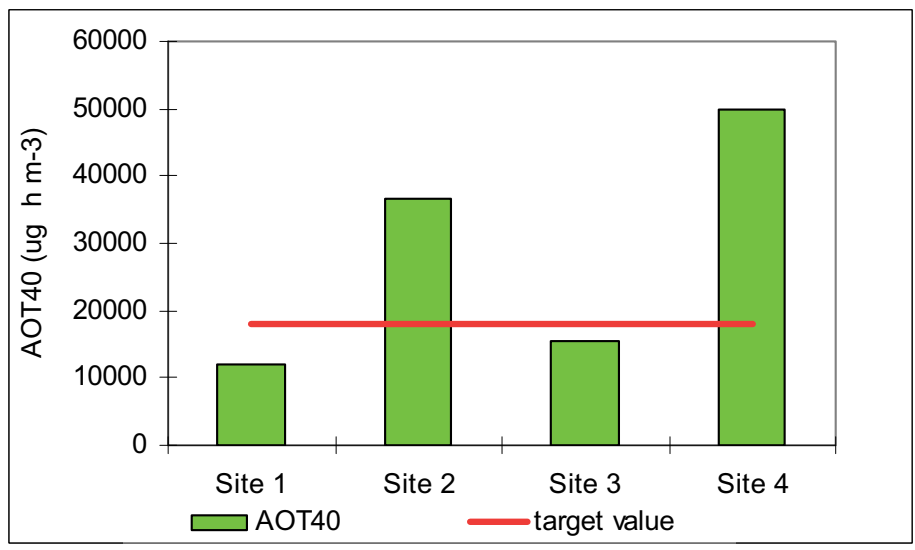

Figure 5. Five years average of $\mathrm{AOT}_{40}$. 
Though the hourly warning level of $180 \mathrm{\mu gm}^{-3}$ is seldom reached (except at Site 4 in the period 2003-05), 8-hour running mean values easily exceed $120 \mathrm{\mu gm}^{-3}$ for more than 25 days per year, especially at the Sites 2 and 4 . The same target value is exceeded in the 3-years average at both cited Sites (Tab. 1).

Table 1. Number of days per year with 8-hour mean values exceeding $120 \mathrm{\mu gm}^{-3}$.

\begin{tabular}{|c|c|c|c|c|c|c|c|c|}
\hline Site & \multicolumn{2}{|c|}{ Site 2 } & \multicolumn{2}{c|}{ Site 1 } & \multicolumn{2}{c|}{ Site 3 } & \multicolumn{2}{c|}{ Site 4 } \\
\hline Year & $\mathrm{n}>120$ & 3 -y av & $\mathrm{n}>120$ & 3-y av & $\mathrm{n}>120$ & 3 -y av & $\mathrm{n}>120$ & 3-y av \\
\hline 2003. & & & 12 & & 1 & & 60 & \\
2004. & 18 & & 1 & & 8 & & 89 & \\
2005. & 37 & 28 & 4 & 6 & 13 & 7 & 130 & 93 \\
2006. & 22 & 26 & 3 & 3 & 0 & 7 & 0 & 73 \\
2007. & 14 & 24 & 1 & 3 & 5 & 6 & 1 & 44 \\
\hline
\end{tabular}

\section{CONCLUSION}

Though an increase in ozone levels was recently observed in some parts of Europe, there is still a declining trend of ozone in the Rijeka Bay Area. This might be due to still increasing emission of $\mathrm{NO}_{\mathrm{X}}$ from traffic, though overall emission of $\mathrm{NO}_{\mathrm{X}}$ are not significantly changed since 2001. Except at Site 2, concentration roses indicate local pollution sources as sources of ozone.

The 5-y average of $\mathrm{AOT}_{40}$ values exceed the target value for vegetation at the remote areas, Site 4 and Site 2 . The latter Site is a coastal resort well known for its rich Mediterranean vegetation, and the possible impacts of such high $\mathrm{AOT}_{40}$ values should be considered.

The air pollution with ozone is strongly dependent on the local meteorological conditions. The highest number of days exceeding the running 8-hour target value for human health protection was observed in 2005 . due to long warm summer. The exception is Site 1, with highest number of exceedences registered during summer 2003 heat wave.

Acknowledgments: The financial support by the Croatian Ministry of Science, Education and Sport (grants No. 062-0621341-0308 and No. 098-0982915-2947) is gratefully acknowledged. Technical assistance from Mr. V. Zubak is very appreciated.

\section{REFERENCES}

Avino, P. and M. Manigrasso, 2008: Ten-year measurements of gaseous pollutants in urban air by an open path analyzer. Atmos Environ., 42, 4138-4148.

Butkovic, V., T. Cvitas, K. Dzepina, N. Kezele and L. Klasinc, 2002: Long-term ozone data analysis. Croat Chem Acta, 75, 927-933.

Ebi, K.L. and G. McGregor, 2008: Climate change, tropospheric ozone and particulate matter and health impacts. Environ Health Perspect, doi: 10.1289/ehp.11463 (http://dx.doi.org/)

ETC/ACC Technical paper 2007/1, Chapter 3.7. Ozone, 38-53. 